2 Beinart J. A History of the Nuffield Department of Anaesthetics, Oxford 1937-1987. Oxford: University Press, 1987.

3 Letter from H. Griffith to R. Macintosh. 17th June 1942. Contemporary Medical Archives. London: Wellcome Institute for the History of Medicine.

4 Macintosh RR. Anaesthetics research in wartime. Med Times $1945 ; 253-5$.

5 Macintosh RR. The role of curare. Practitioner 1946; 157: 306

6 Letter from R. Macintosh to H. Griffith. 25th June 1945. Contemporary Medical Archives. London: Wellcome Institute for the History of Medicine.

\section{Paint chips and glass ampoules}

To the Editor:

Many pharmaceutical manufacturers use paint stripes to help identify their ampoules. We would like to warn their users of the potential risk for drug contamination when a paint stripe is applied over the "scored" neck of a glass ampoule.

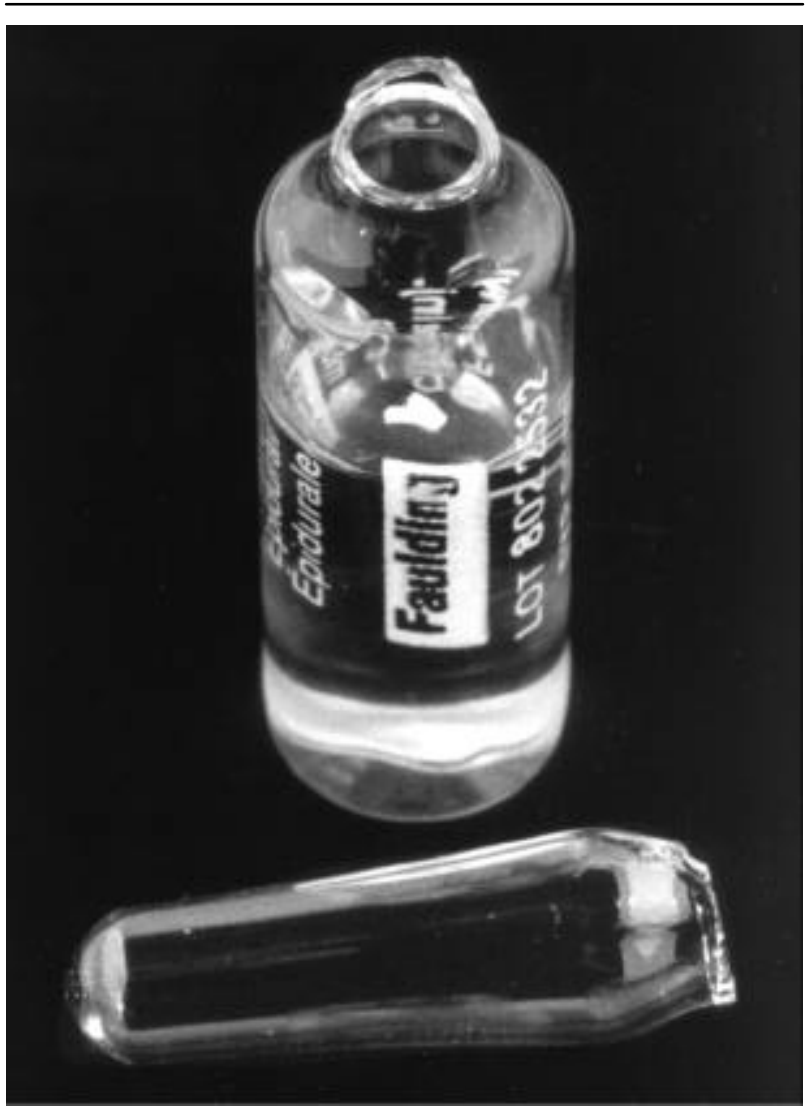

FIGURE Fentanyl ampoule. Note the paint chip floating on the surface of the liquid
Our pharmacy purchases fentanyl from Faulding (Canada) Inc. Their glass ampoules $(2 \mathrm{ml}$ size) have a yellow stripe of paint around the "scored" neck of the ampoule.(Figure) The ampoule is "snapped" open in the usual fashion by placing the top between the thumb and the proximal phalanx of the index finger.

On two separate occasions, a fleck of yellow paint was noticed to be floating on the surface of the liquid inside the ampoule. It was evident on careful inspection that a portion of the yellow paint from the outside of the ampoule was missing. Presumably, the paint chip became detached from the glass and fell into the ampoule while it was being opened. This was noticed prior to intrathecal injection of the medication in both instances.

There have been several case reports of drug contamination by glass particles when opening glass ampoules. ${ }^{1-3}$ In such instances, the use of a filter needle may guard against the intrathecal injection of particulate matter. However, the outside surface of the ampoule is certainly not sterile. If the paint chip had gone unnoticed, a solution that was potentially contaminated with bacteria could have been administered.

Acknowledgments

The authors wish to thank John Hendrix for providing the photograph and Michael Heffer for pharmaceutical advice.

Mark L. Glube MD

Judith Littleford MD BSC FRCPC

Toronto, Ontario

\section{References}

1 Katz H, Borden H, Hischer D Glass particle contamination of color-break ampules. Anesthesiology 1973; 39: 354 .

2 Carbone-Traber KB, Shanks CA. Glass particle contamination in single-dose ampules. Anesth Analg 1986; 65: 1361-3.

3 Turko S, Davies $\mathrm{N}$. Glass particles in intravenous injections. N Engl J Med 1972; 287: 1204.

REPLY:

Thank you for your letter. On November 12, 1999, we received information from $M r$. Heffer at The Mount Sinai Hospital concerning a report of a paint fleck in an ampoule of fentanyl citrate, as a result of opening the ampoule. A reply was sent to Mr. Heffer the same day, informing him that an alternate ampoule format was currently under evaluation. Another follow-up response was sent on Jan. 26, 2000. 
Faulding have now completed trials investigating an alternate ampoule proposed for use with fentanyl citrate. This information is now under review to determine how this design may be introduced to the Canadian market. We take all comments from our customers seriously as we recognise their value in helping to improve the excellence of our products and services. As such, we appreciate the opportunity to comment on the letter and to share the actions of our company.

Scott Armour

Regulatory Affairs Associate

Faulding Canada Inc.

\section{Egress of air through minitracheostomy tube: a dilemma about its position}

To the Editor:

Retention of tracheobronchial secretions is a frequent cause of morbidity in patients with neuromuscular disorders. The advantages of minitracheostomy over more traditional methods of dealing with sputum retention have been described. ${ }^{1,2}$ We report a complication of minitracheostomy which was otherwise unsuspected.

A 29-yr-old woman was referred with progressive muscle weakness in all limbs, difficulty in swallowing and breathing and ineffective cough and was diagnosed as Guillain Barré Syndrome based on nerve conduction studies. After tracheal intubation and pressure support ventilation, she showed rapid motor recovery but was unable to clear her respiratory secretions. Extubation and minitracheostomy were planned.

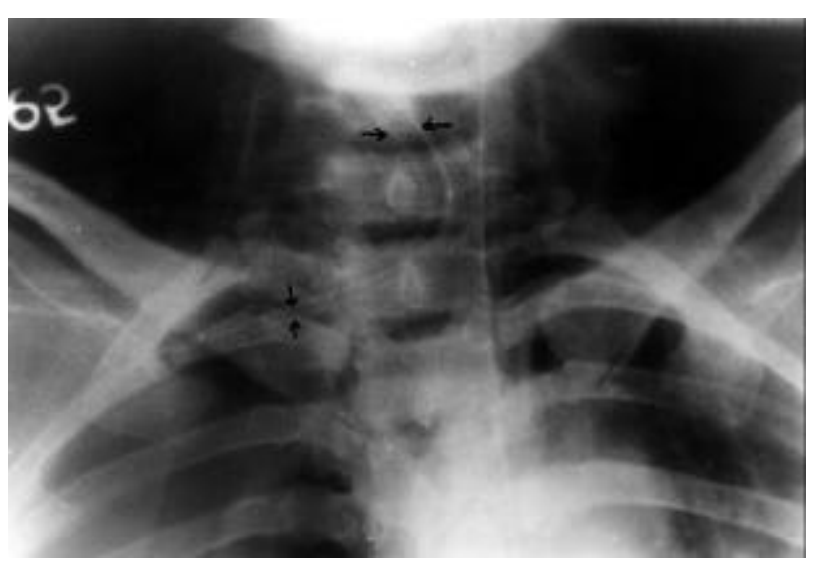

FIGURE -Position of minitracheostomy and right side pneumothorax in chest Ray AP view.
Al6-gauge needle was introduced between lst and 2nd tracheal rings, air aspirated and a guide wire passed, the latter requiring some force. The internal diameter tracheal cannula was then slid over the guide wire and fixed in position. The position was checked by aspirating air through the minitracheostomy tube and, with every breath, air moved freely in and out of the tube. However no secretions could be aspirated even after instilling saline. Chest $\mathrm{X}$ ray revealed the cannula tip in the right pleural space and right side pneumothorax with collapsed lung parenchyma (Figure). The cannula was removed and the patient was managed with a nasotracheal tube.

Chest X-ray usually confirms the proper position of tracheostomy. In cases where negotiation of the guide wire is not smooth, the absence of tracheal secretion should raise suspicion about the malposition of tracheostomy tube.

Chandra Kant Pandey MD

Devashish Chakravarty MD PDCC

Namita Singh MD PDCC

Rehana Sikora MD

Lucknow, India

\section{References}

1 Matthews HR, Hopkinson RB. Treatment of sputum retention by minitracheotomy. Br J Surg 1984; 71: $147-50$.

2 Yeoh NTL, Wells FC, Goldstraw P. A complication of minitracheostomy. Br J Surg 1985; 72: 633. 